\title{
Cicatrização de ferida profunda em equino com uso de drenagem aberta, laser de baixa intensidade e ultrassom terapêutico - relato de caso
}

Gustavo Henrique Marques Araujo, Anna Beatriz Borges de Carvalho, Guilherme Pinheiro Santos, Jordana Cabral Rosa dos Anjos, Rhavilla Santos de Oliveira, Rogerio Elias Rabelo, Julia de Miranda Moraes

*Autor correspondente

e-mail: gustavoaraujovet@gmail.com

\section{Resumo}

Lesões cutâneas possuem ampla importância na clínica equina por terem um período de cicatrização extenso e desenvolvimento de tecido de granulação em excesso. Várias linhas de pesquisas buscam estratégias para driblar intercorrências indesejadas durante o processo de reparação tecidual dos equinos. A técnica de drenagem aberta pode ser empregada na clínica de grandes animais quando o fechamento primário da lesão não pode ser realizado, seja ele em casos de contaminação da ferida ou em casos de áreas muito extensas. Os drenos ativos são sistemas de sucção fechados, que removem o fluído por pressão negativa, sendo particularmente úteis na drenagem de feridas profundas, e apresentam menor risco de infecção. Outros métodos como o laser de baixa potência (LBP) e ultrassom terapêutico (UST) são frequentemente empregados no tratamento de lesões cutâneas, impulsionando a produção de colágeno e o ágil desenvolvimento de fibroblastos, o que implica em aumento da força de tensão da ferida e redução do tempo de cicatrização. Entre os benefícios estão listados a ação analgésica, propriedades anti-inflamatórias, redução do edema e estímulo do fluxo sanguíneo. Objetivou-se relatar a reconstituição tecidual de lesão cutânea em um equino. Foi atendido um equino, macho, de aproximadamente quatro anos de idade, clinicamente debilitado, apresentando lesão cutânea exsudativa, visualmente contaminada, com bordas irregulares e elevadas, edematosas, invaginadas, profundidade acentuada. Localizada cranialmente à região inguinal esquerda, lateralmente ao prepúcio. 0 proprietário não soube informar o evento desencadeante da lesão e a procura por atendimento ocorreu cinco dias após a identificação. Optou-se pelo acompanhamento e cicatrização por segunda intenção, higienizando a ferida com líquido de Dakin e clorexidine, antibioticoterapia (penicilina procaína $30.000 \mathrm{UI} / \mathrm{Kg}$, SID, durante 10 dias) e AINE (fenilbutazona 4,4 mg/Kg, SID, durante 4 dias). Os curativos eram feitos duas vezes ao dia e pretendiam combater a infecção da ferida e proporcionar um ambiente favorável para cicatrização, com remoção de sujidades, tecidos necróticos e manutenção 
da umidade ideal. Além da terapia medicamentosa, optou-se pelo uso do dreno ativo durante seis dias, facilitando a manutenção da limpeza da ferida e excreção de conteúdo acumulado. A terapia com LBP e UST ocorreu em duas etapas, sendo a primeira no $5^{\circ}$ e no $7^{\circ}$ dia após o início do tratamento, quando foi aplicado LBP (Physiolux dual, $830 \mathrm{~nm}$ de comprimento de onda, Arsenieto de Gálio e Alumínio-AsGaAl, potência de $40 \mathrm{~mW}$ - Bioset) com 20 Joules $/ \mathrm{cm}^{2}$ de intensidade, nas bordas da ferida de forma pontual, em pontos equidistantes de $1 \mathrm{~cm}$, e em varredura sobre o leito da ferida. Após 37 dias, a ferida encontravase com $39.9 \mathrm{~cm}^{2}$ e atingia a granulação e nivelamento desejado, dando início à segunda fase. Nessa etapa, a terapia com LBT foi retomada, aplicando-se $10 \mathrm{~J} / \mathrm{cm}^{2}$ nas bordas, associada com UST (Sonacel Dual Bioset) aplicado pelo método direto, na presença de gel, sobre a pele tricotomizada, com frequência de $3 \mathrm{MHz}$ no modo pulsado (não-térmico), intensidade de 0,5W/cm² e intensidade de pulso a $100 \mathrm{~Hz}$ a $10 \%$ por 12 minutos sobre as linhas de tensão, nas áreas de formação de fibrose e aderência (cinco aplicações a cada dois dias). Após 90 dias do início do tratamento, a ferida apresentava $7,6 \mathrm{~cm}^{2}$, demonstrando redução de $81 \%$ em sua extensão em comparação com a extensão evidenciada na segunda fase da terapia com LBP e UST. A combinação das duas técnicas apresentou resultados satisfatórios, diminuindo consideravelmente o tempo de cicatrização, com interessante resultado estético.

Palavras-chave: Ferida. Dreno aberto. Laserterapia. 